UDC 615.072: 543.42.062

DOI: $10.15587 / 2519-4852.2020 .215287$

\title{
A STUDY OF THE INFLUENCE OF THE TEST SAMPLE INHOMOGENEITY ON VARIABILITY IN ASSAY RESULTS OF DESLORATADINE IN FILM-COATED TABLETS
}

\author{
D. Leontiev, V. Petrus, N. Volovyk, O. Gryzodub
}

\begin{abstract}
Aim. The work aimed at metrological evaluation and management of the risk of inconsistency in the results of desloratadine assay in film-coated tablets.

Materials and methods. A pilot-scale batch of the pharmaceutical preparation Alerdez served as a study object. Spectrophotometric readings were performed on a UV-Vis spectrophotometer Lambda 25 at $282 \mathrm{~nm}$. An analytical balance Mettler Toledo, pH-meter Metrohm, Class A volumetric pipettes and flasks were used for analysis. The test sample was prepared by manual tablet grinding.

Results and discussion. A trend of obtaining inconsistent assay results with a systematic shift towards an increase while taking test portions in sequence was observed. This may inform a test sample inhomogeneity, which may be reduced by increasing a test portion mass. An experiment design to study the impact of the test portion mass on the variability in assay results was laid down. A prognosis for the minimum test portion mass contributing to the mitigation of the risk of the test sample inhomogeneity was scientifically justified and experimentally verified. Acceptance criteria for the assessment of the test sample homogeneity by assay results were established based on the principle of insignificance and recommendations of the State Pharmacopoeia of Ukraine to the target measurement uncertainty. A procedure for desloratadine assay intended to be used for the method transfer and routine analysis, as well as acceptance criteria for assay results, was developed. Their feasibility was experimentally proved during method transfer. The greater difference between the values obtained in the receiving unit compared to those collected in the sending unit was observed, yet the results met the acceptance criteria.

Conclusions. This paper provides comprehensive solutions that allow for minimizing the risk of variability in desloratadine assay results. The risk of aberrant assay results could be mitigated by using a test portion equivalent to the weight of four tablets (approx. $420 \mathrm{mg}$ )
\end{abstract}

Keywords: desloratadine tablets, sample preparation, comminution, homogeneity acceptance criteria, assay result uncertainty

Copyright (C) 2020, D. Leontiev, V. Petrus, N. Volovyk, O. Gryzodub. This is an open access article under the CC BY license (http://creativecommons.org/licenses/by/4.0).

\section{Introduction}

Assay is an essential quality attribute of medicines. Accurate assay results are critical for making informed accept/reject decisions. However, sometimes aberrant assay results are observed, and the root cause should be investigated [1].

In the European Union, for assays of finished drug products (FDPs), the content limits of $\pm 5 \%$ are considered acceptable without further justification; the use of wider limits has to be justified $[2,3]$. Along with this, FDPs should meet the requirements for uniformity of dosage units (UDU), harmonised between the European Pharmacopoeia (Ph. Eur.), the U.S. Pharmacopeia (USP) and the Japanese Pharmacopoeia, that allow deviation in the amount of an active pharmaceutical substance among dosage units up to $25 \%$ of the amount claimed [4]. Such a significant deviation may lead to inconsistent assay results provided a test sample is not sufficiently representative. In this regard, an assay result should be obtained from a representative test sample of the dosage units with subsequent averaging of the result [5]. For solid dosage forms
(SDFs), 20 units are generally accepted to be a representative sample size. The use of a lesser number of SDF units increases the risk of making wrong or inconsistent decisions about the compliance of medicines with specifications in the event the method uncertainty and the content variability between SDF units are close to the maximum allowable values [6].

Earlier we have shown that for FDPs, the requirements for the content limits of $\pm 5 \%$, target uncertainty of the assay results and UDU test are consistent provided an averaging of 20 SDF units is used for assay [7].

The most reliable technique to obtain a representative test sample for analysis is to dissolve 20 tablets to prepare a test solution. However, the use of this technique may create difficulty in the event an analyte has limited solubility in the selected solvent. Therefore, a conventional approach for preparation of a test sample for assays of tablets, including film-coated ones, is to grind the dosage units by hand to a visually homogeneous powder from which a test portion is then taken for the analysis [8]. 
The criterion of visual homogeneity is quite subjective. Scarce literature reports techniques of sieving, increasing comminution time, dispersing the coating material, and the use of electric mills to solve the possible issue with the test sample inhomogeneity. However, each of them has its drawbacks and cannot itself provide a reliable solution to the problem. Therefore, manual grinding of dosage units is considered by many a preferred technique as being the simplest one. The method of sample averaging has been shown to run the risk of obtaining an inhomogeneous test sample, whichever technique is used $[9,10]$. However, the authors neglected to quantify this risk. Since no acceptance criteria for sufficient test sample homogeneity were established, the risk of making inaccurate or inconsistent conclusions about medicine compliance exists. While there is a well-known technique to reduce the impact of the test sample inhomogeneity by increasing a test portion mass [11, 12], management of the risk by this technique, as far as we know, has not been reported yet. Thus, in spite of the existent issue, the risk of inaccurate or contradictory assay results on account of insufficient homogeneity of the test sample when obtained in another laboratory or over time remains out of control.

During method development for desloratadine assay in pharmaceutical preparation Alerdez, film-coated tablets containing $5 \mathrm{mg}$ of desloratadine, manufactured by PJSC SIC "Borshchahivskiy CPP", Ukraine, we obtained assay results significantly underestimated compared to those calculated from the UDU test. For the procedure, a spectrophotometric method in the UV region was chosen. The use of organic solvents in which desloratadine is readily soluble led to the unacceptably high absorption of the placebo solution. When chosen $0.1 \mathrm{M}$ hydrochloric acid as a solvent, the use of which for quantification of desloratadine is described in the literature [13], the absorption of the placebo solution was relatively low. Given poor solubility of desloratadine in $0.1 \mathrm{M}$ hydrochloric acid, grinding of dosage units was chosen as a sample preparation technique. For the preparation of the test solution, a test portion was taken from the averaged test sample resulting from comminution of 20 tablets of desloratadine by hand to a visually homogeneous powder. The procedure was validated using model solutions by the approach of the State Pharmacopoeia of Ukraine (SPhU) described in the general text 5.3.N.2. Validation of analytical procedures [14].

It should be noted that a number of works describe development and validation of the procedure for assay of desloratadine in film-coated tablets, in which a test sample is obtained by grinding 20 tablets [15-20]. However, none of them addresses the problem of managing variability in assay results associated with the test sample inhomogeneity.

In view of this, management of the risk of inhomogeneity of the test sample by reason of manual comminution technique is of vital importance.

This work aimed at metrological evaluation and management of the risk of inconsistency in the results of desloratadine assay in film-coated tablets.

\section{Planning (methodology) of research}

Manual tablet grinding is still a widely employed technique for quantification of desloratadine, though proved to be challenging for ensuring sufficient homogeneity of the test sample resulting in variability in assay results. To ensure acceptable homogeneity of the test sample and to minimize the risk of aberrant assay results, there was a need to set out an experiment design, establish metrologically sound acceptance criteria based on the state-of-the-art approaches, and propose a procedure suitable for the method transfer and routine analysis of the pharmaceutical preparation Alerdez, $5 \mathrm{mg}$ desloratadine film-coated tablets.

Analytical procedures are designed to be suitable for the intended use [21]. The World Health Organization recommends using different analytical methods to define the most acceptable one, considering their suitability and affordability [22]. For desloratadine tablets, USP offers an HPLC method for assay and a spectrophotometric method for the dissolution test [23]. The use of the spectrophotometric method is advantageous over an HPLC method in terms of costs and time. It is widely used for quantification of active pharmaceutical substances, including desloratadine. Therefore, a spectrophotometric method was chosen for the study of variability in assay results. Fulfilment of the aim of the research required the development of a feasible and reproducible procedure for desloratadine assay based on scientificbased acceptance criteria.

\section{Materials and methods}

A pilot-scale batch of the pharmaceutical preparation Alerdez, $5 \mathrm{mg}$ desloratadine film-coated tablets manufactured by PJSC SIC "Borshchahivskiy CPP", Ukraine, served as a study object. Excipients: calcium hydrogen phosphate dihydrate, cellulose, maize starch, talc, hypromellose, macrogol 400 (PEG 400), macrogol 4000 (PEG 4000), polyvinyl alcohol, titanium dioxide, indigo-carmine colouring. The content of desloratadine is specified to range from $4.75 \mathrm{mg}$ to $5.25 \mathrm{mg}(5 \mathrm{mg} \pm 5 \%$ ) per tablet. The tablet weight is about $105 \mathrm{mg}$.

For quantification of desloratadine, a spectrophotometric method in the UV region was employed. Readings were performed on a UV-Vis spectrophotometer Lambda 25 equipped with a $1-\mathrm{cm}$ cuvette (Perkin Elmer) at $282 \mathrm{~nm}$.

For the study, we also used an analytical balance Mettler Toledo XP 205DR, pH-meter Metrohm, Class A volumetric pipettes and flasks, PTFE filter with pre-filter $0.45 \mu \mathrm{m}$ cat. No. SYTG0602MNXX104 manufactured by MDI.

For the preparation of a reference solution, an SPhU reference standard of desloratadine suitable for assay by UV-Vis spectrophotometry was used (assigned value: $99.7 \%$, target uncertainty: NMT $0.5 \%$ expressed as a one-tailed confidence interval for a probability of $95 \%$ ).

Test Sample. Weigh and grind 20 randomly chosen tablets to a visually homogeneous powder using a mortar and pestle.

Test solution. Transfer a test portion taken from the test sample to a volumetric flask, add $0.1 \mathrm{M}$ hydro- 
chloric acid, and sonicate for about $20 \mathrm{~min}$ with intermittent manual shaking. Cool and dilute the content of the flask to volume with the same solvent, and mix. Pass through a filter and use the filtrate.

By the manufacturer's procedure, a test portion equivalent to the tablet weight (about $105 \mathrm{mg}$ ) is dispersed in a $250 \mathrm{~mL}$ volumetric flask. In the study, test portions of $105 \mathrm{mg}, 210 \mathrm{mg}$, and $420 \mathrm{mg}$ (equivalent to the weight of one, two, and four tablets, respectively) were used. The test portions were dissolved in the solvent correspondingly in a $250 \mathrm{~mL}, 500 \mathrm{~mL}$, and $1000 \mathrm{~mL}$ volumetric flasks.

Reference solution. Dissolve $40 \mathrm{mg}$ of an SPhU desloratadine reference standard in $100 \mathrm{~mL}$ of $0.1 \mathrm{M}$ hydrochloric acid. Dilute $5.0 \mathrm{~mL}$ of the resulting solution with the same solvent to volume in a $100 \mathrm{~mL}$ volumetric flask.

The content of desloratadine $\left(x_{i}\right)$ per tablet, expressed in $\mathrm{mg}$, is calculated by Eq. (1).

$$
x_{i} \quad \begin{array}{cccccc}
A_{1} & m_{0} & P & b & 5 & V_{1} \\
\cline { 2 - 5 } & m_{0} & 100 & 100 & 100
\end{array},
$$

where $A_{1}-$ absorbance of the test solution;

$A_{0}$ - absorbance of the reference solution;

$m_{0}$ - test portion mass of the SPhU desloratadine reference standard, $\mathrm{mg}$;

$m_{l}$ - test portion mass of the test sample, $\mathrm{mg}$;

$P$ - value assigned to the $\mathrm{SPhU}$ desloratadine reference standard, per cent;

$V_{l}$ - volume of $0.1 \mathrm{M}$ hydrochloric acid in the test solution, $\mathrm{mL}$;

$b$ - average tablet mass, mg.

\section{Results}

When developing a procedure for quantification of desloratadine in film-coated tablets Alerdez, assay results significantly underestimated in comparison with those calculated from the UDU test were obtained, which may be explained by segregation of the test sample while taking test portions caused by substantial physical differences between a tablet coat and a tablet core [9]. If this is a case, there should be a trend of obtaining increasingly higher assay results while taking test portions in sequence. To the best of our knowledge, studies investigating inconsistent assay results on the assumption of inhomogeneity of the test sample introduced during test portion taking have not been reported in the literature.

Evidently, while using a test sample prepared by manual grinding of film-coated tablets, the following risks are possible:

1) unacceptably high variability in assay results;

2) a systematic shift in the assay results in the course of taking test portions in sequence (either from higher to lower or lower to higher values).

The risks can be mitigated by increasing a test portion mass. Theoretically, doubling a test portion mass is comparable to the performance of two independent analyses followed by averaging of results [11].

Considering all the above, to study the influence of the test portion mass on the variability in deslorata- dine assay results, we offer an experiment design as follows:

"Obtain a visually homogeneous test sample by grinding 20 tablets to powder. Take test portions sequentially recording their numbers $\left(n_{i}\right)$ and assay desloratadine by the manufacturer's procedure until the test sample has run out.

Calculate assay results $\left(x_{i}\right)$ in percentages of the nominal concentration of desloratadine in tablet by Eq.1. Calculate a one-tailed confidence interval for the values of $x_{i}\left(\Delta_{i}\right)$."

Here and further, a confidence level is $95 \%$.

For evaluation of assay results, we propose to calculate a least-squares regression line by Eq. 2 .

$$
x_{i}=a+b \times n_{i,},
$$

where $x_{i}-$ nominal concentration of desloratadine per tablet, per cent (dependent variable);

$$
\begin{aligned}
& a \text {-intercept; } \\
& b \text {-slope; } \\
& n_{\mathrm{i}} \text { - number of the test portion (independent vari- }
\end{aligned}
$$
able).

For the assessment of homogeneity of the test sample, we propose acceptance criteria that rely on the principle of insignificance [24] and SPhU approaches to the target measurement uncertainty for assay of FDPs $\left(U_{\text {target }}\right)$ described in the general text 5.3.N.1. Statistical analysis of the results of a chemical experiment [14], according to which the following requirement for FDPs with content limits $( \pm B)$ have to be met:

$$
U_{\text {target }}=0.32 \times B \text {, }
$$

where $U_{\text {target }}$ is expressed as a one-tailed confidence interval.

The use of the coefficient of 0.32 ensures insignificance of the partial constituent of uncertainty at a confidence level of $95 \%$.

For $B=5 \%$, the requirement for uncertainty of the assay result: $U_{\text {target }}=1.6 \%$.

Hence, we propose the following acceptance criteria for assay results:

1. Criterion for the result reliability:

$$
\text { i } U_{\text {target }} \text {, }
$$

which is for the study object: $\Delta_{i} \leq 1.6 \%$.

2. Criterion of statistical insignificance for $b$ :

$$
b \quad b \text {, }
$$

where $\Delta_{b}$ - two-tailed confidence interval.

3 . In the event of failure to comply with criterion 2 (if $b$ differs significantly from zero), the criterion of practical insignificance of segregation is proposed:

$$
\left|x_{1 \text { Calc }} \quad x_{\max \text { Calc }}\right| \quad 1.6 \% \text {, }
$$

where $x_{1 \text { Calc }}$ - assay value calculated from the regression line for $n_{l}$ (the first test portion analyzed); 
$x_{\max \text { Calc }}$ - assay value calculated from the regression line for $n_{\max }$ (the last test portion analyzed).

For the above approach to work correctly, an analytical procedure should be validated using model solutions, and an uncertainty assessed from the validation results $\left(\Delta_{V a l}\right)$ should be reasonably small for the inhomogeneity study.

By ISO 17034, an analytical procedure is considered acceptable for the inhomogeneity study if $\Delta_{V a l} \leq U_{\text {target }}$, i.e. if $\Delta_{V a l} \leq 1.6 \%$ [25]. However, it is advisable that $\Delta_{V a l}$ uncertainty is insignificant with respect to the acceptance criterion:

$$
\text { Val } \quad 1.6 \% \quad 0.32 ; \text { Val } \quad 0.51 \% \text {. }
$$

The results of the assay procedure validation conducted prior this study have shown that $\Delta_{V a l}=0.55 \%$, where $\Delta_{V a l}$ is a confidence interval for recovery calculated from the results of the study of linearity on 9 model solutions [14]. Apparently, the obtained value of $\Delta_{V a l}$ is acceptable and very close to the most stringent criterion.

To verify the established acceptance criteria, we carried out an experimental study.

We started from the test portion mass equivalent to the weight of one tablet $(105 \mathrm{mg})$ since in this case, the analytical procedure was also suitable for the UDU test.

The assay and calculation results obtained for the test portions of $105 \mathrm{mg}$ are shown in Table 1 .

A graphical presentation of the assay results, as well as the regression line calculated from them, is given in Fig. 1.

Table 1

Results of desloratadine assay and calculation obtained for the test portion of $105 \mathrm{mg}$

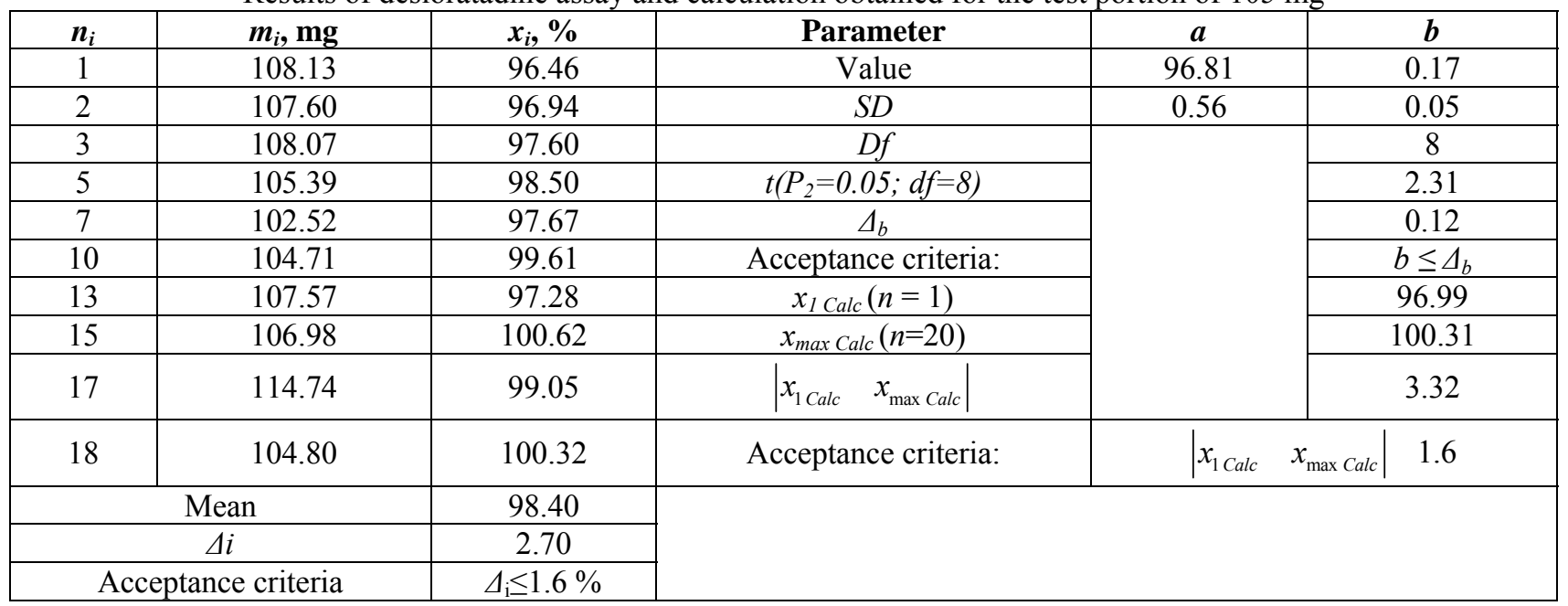

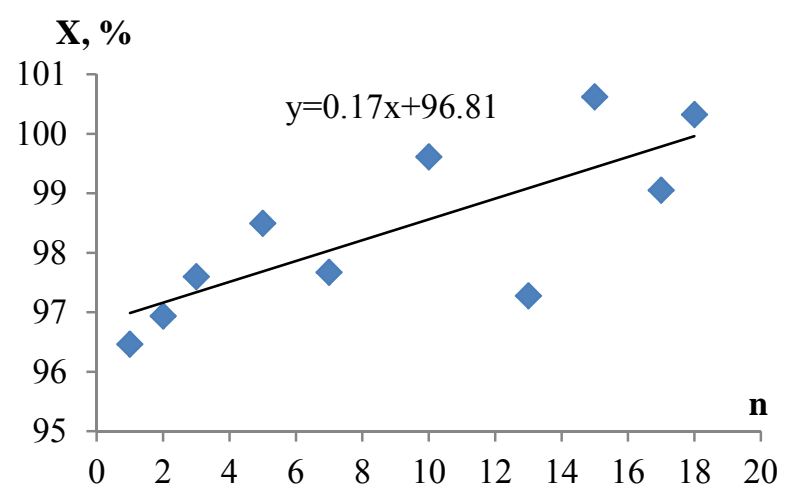

Fig. 1. Assay results obtained for the test portion of 105 $\mathrm{mg}$ and the regression line

As seen from Table 1, the confidence interval for assay results $(\Delta i)$ is twice the acceptance criteria. Furthermore, there is a systematic shift in the assay results from lower to higher values. The slope of the calculated regression line is statistically significant for a $95 \%$ confidence level. The difference between assay results obtained for the first and last test portions calculated from the regression line is twice as much as the acceptance criteria. Therefore, the use of the test portion mass equi- valent to the weight of one tablet $(105 \mathrm{mg})$ is unacceptable as it does not ensure the required uncertainty of assay results.

Considering all the above, we conducted a theoretical prognosis for the test portion mass suitable for assay $\left(m_{\text {theor }}\right)$. We proceeded on the assumption that an increase in the test portion mass by $n$ times decreases variability caused by inhomogeneity by $\sqrt{ } n$ times:

$$
\begin{aligned}
& m_{\text {theor }}=m_{i} \times\left(\Delta_{i} / 1.6\right)^{2}=105 \times(2.7 / 1.6)^{2}=300 \mathrm{mg} \\
& m_{\text {theor }}=m_{i} \times\left(\mid x_{1 \text { Calc }}-x_{\max \text { Calc }} / / 1.6\right)^{2}= \\
& =105 \times(3.3 / 1.6)^{2}=450 \mathrm{mg} .
\end{aligned}
$$

Eq. (8) and (9) are based on the results for the one-tailed confidence interval for the assay values $(\Delta \mathrm{i})$ and the difference between assay values obtained for the first $(n=1)$ and last $(n=20)$ test portions calculated from the regression line, respectively.

On the grounds of the results obtained, the test portion mass should be increased fourfold. As desloratadine is slightly soluble in the selected solvent 
(0.1 M hydrochloric acid), an increase in the test portion mass and the solvent volume should be done.

Therefore, the following amendment to the manufacturer's procedure for the test solution preparation was made:

"Transfer a test portion of the test sample equivalent to the weight of four tablets (about $420 \mathrm{mg}$ ) to a $1000-\mathrm{mL}$ volumetric flask. Add $800 \mathrm{~mL}$ of $0.1 \mathrm{M}$ hydrochloric acid and sonicate for about 20 min with intermittent manual shaking. Cool and dilute the content of the flask to volume with the same solvent, and mix. Pass through a filter and use the filtrate."

To verify the abovementioned prognosis, it was necessary to perform an assay using test portions increased by two and four times compared with the manufacturer's procedure.
For the use of the test portion increased by two times, the following amendment to the manufacturer's procedure for the test solution preparation was made:

"Transfer a test portion of the test sample equivalent to the weight of two tablets (about $210 \mathrm{mg}$ ) to a 500$\mathrm{mL}$ volumetric flask. Add $400 \mathrm{~mL}$ of $0.1 \mathrm{M}$ hydrochloric acid and sonicate for about $20 \mathrm{~min}$ with intermittent manual shaking. Cool and dilute the content of the flask to volume with the same solvent, and mix. Pass through a filter and use the filtrate."

The assay and calculation results obtained for the test portions of $210 \mathrm{mg}$ are shown in Table 2 .

Fig. 2 represents a graphical presentation of the assay results, as well as the regression line calculated from them.

Table 2

Results of desloratadine assay and calculation obtained for the test portion of $210 \mathrm{mg}$

\begin{tabular}{|c|c|c|c|c|c|}
\hline$n_{i}$ & $m_{i}, \mathbf{m g}$ & $x_{i}, \%$ & Parameter & $a$ & $b$ \\
\hline 1 & 212.40 & 98.27 & Value & 98.82 & 0.23 \\
\hline 2 & 214.40 & 99.34 & $S D$ & 0.36 & 0.06 \\
\hline 3 & 220.90 & 100.12 & $D f$ & & 8 \\
\hline 4 & 211.60 & 100.34 & $t\left(P_{2}=0.05 ; d f=8\right)$ & & 2.31 \\
\hline 5 & 219.40 & 100.42 & $\Delta_{b}$ & & 0.14 \\
\hline 6 & 208.80 & 99.45 & Acceptance criteria: & & $b \leq \Delta_{b}$ \\
\hline 7 & 219.30 & 100.11 & $x_{1 \text { Calc }}(n=1)$ & & 99.05 \\
\hline 8 & 208.50 & 100.82 & $x_{\max \text { Calc }}(n=10)$ & & 101.11 \\
\hline 9 & 206.40 & 100.90 & $\left|x_{1 \text { Calc }} \quad x_{\max \text { Calc }}\right|$ & & 2.07 \\
\hline 10 & 201.40 & 101.06 & Acceptance criteria: & $\left|\begin{array}{ll}x_{1 \text { Calc }} & x_{\max \text { Calc }} \mid\end{array}\right|$ & 1.6 \\
\hline \multicolumn{2}{|c|}{ Mean } & 100.08 & & & \\
\hline \multicolumn{2}{|c|}{$\Delta i$} & 1.57 & & & \\
\hline \multicolumn{2}{|c|}{ Acceptance criteria } & $\Delta_{\mathrm{i}} \leq 1.6 \%$ & & & \\
\hline
\end{tabular}

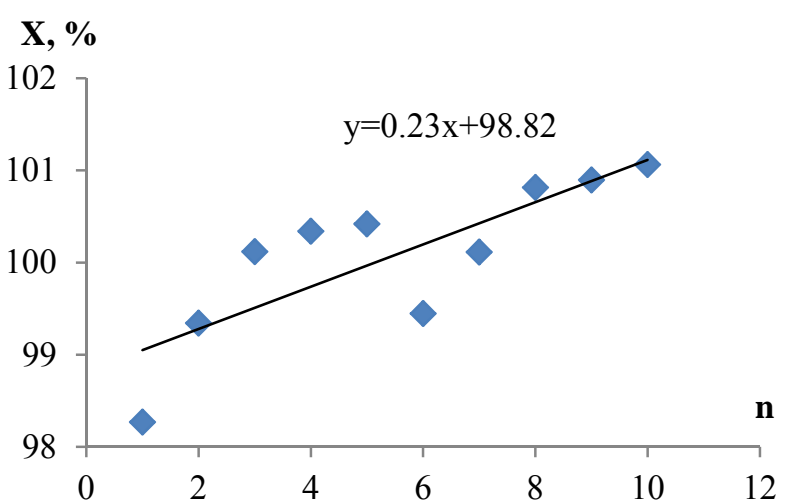

Fig. 2. Assay results obtained for the test portion of $210 \mathrm{mg}$ and the regression line

As seen from Table 2, the confidence interval for the assay results $(\Delta i)$ corresponds to the maximum allowable value. The slope of the calculated regression line is still statistically significant for a $95 \%$ confidence level. The difference between assay results obtained for the first and last test portions calculated from the regression line exceeds the acceptance criteria. Therefore, the use of the test portion equivalent to the weight of two tablets $(210 \mathrm{mg})$ is unacceptable. This conclusion is in line with the prognosis made (Eq. (8) and (9)).

The assay results for the test portion of $420 \mathrm{mg}$ are shown in Table 3.

Fig. 3 represents assay results and the regression line calculated from them.

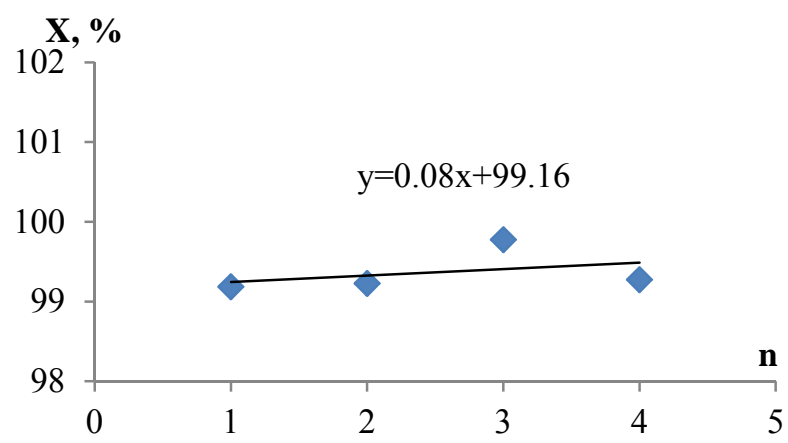

Fig. 3. Assay results obtained for the test portion of $420 \mathrm{mg}$ and the regression line 
Table 3

Results of desloratadine assay and calculation obtained for the test portion of $420 \mathrm{mg}$

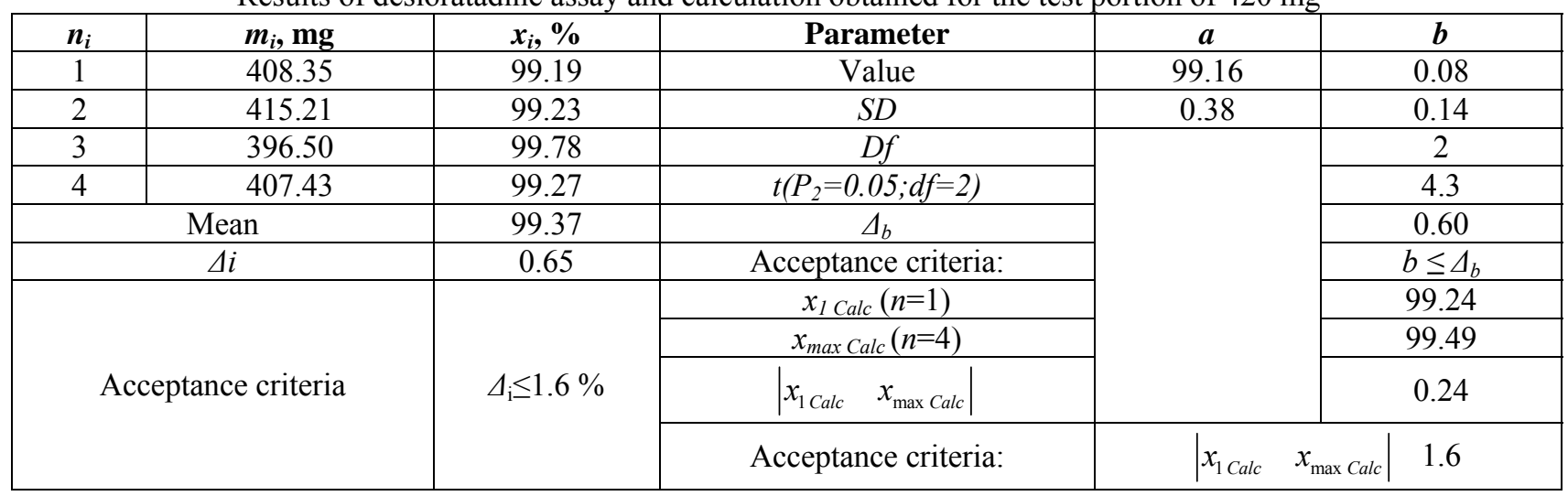

From Table 3, it is noticed that an increase in the test portion to $420 \mathrm{mg}$ resulted in the scatter of the assay results about three times lower than the maximum acceptable. The standard deviation decreased sixfold as opposed to the expected halving. The resulting uncertainty complied to that obtained during validation using model solutions $\left(\Delta i=0.65 \% ; \Delta_{V a l}=0.55 \%\right)$. It means that variability in the assay results associated with the inhomogeneity of the test sample was reduced to an insignificant level. A plausible explanation for this might lie in the fact that the influence of the test sample segregation when taking test portions in sequence tended to zero owing to a reduction of the number of test portions taking. It should be noted that despite a visually recognised slope of the calculated regression line, a very small degree of freedom leads to a large value of the confidence interval, which means that the slope is statistically insignificant.

Thus the experimental results have shown that an increase in the test portion mass is an effective tool for reducing variability in assay results associated with the inhomogeneity of the test sample. However, given that routine analysis can be performed in timelimited conditions, manual grinding of film-coated tablets is highly likely to be a source of uncontrolled variability in assay results.

Therefore, we propose a metrologically sound procedure for quality control of desloratadine assay results:

"From the test sample obtained by manual grinding of 20 tablets of $5 \mathrm{mg}$ desloratadine filmcoated tablets to a visually homogeneous powder (for approx. $5 \mathrm{~min}$ ), take four consecutive test portions (approx. $410 \mathrm{mg}$ each) and assay according to the procedure.

Calculate a confidence interval of the single value of the analysis results for four test solutions $\left(\Delta_{i}\right)$."

The procedure is intended to be used as an element of the method transfer and analytical control strategy [26]. It can also be used for personnel testing or investigation of out-of-specification results.
Acceptance criteria:

- $\Delta_{i} \leq 1.6 \% \Rightarrow$ pass

$-\Delta_{i}>1.94 \% \Rightarrow$ fail. The cause of the discrepancy should be investigated.

$-1.94 \% \geq \Delta_{i} \geq 1.6 \% \Rightarrow$ ambiguous. An assay using additional 20 tablets should be performed by the proposed procedure (4 test portions per $420 \mathrm{mg}$ ) and calculation of the standard deviation for single assay results and the pooled confidence interval for all assay results $\left(\Delta_{i \text { pool }}\right)$ should be made.

If $\Delta_{i \text { pool }} \leq 1.6 \% \Rightarrow$ pass.

If $\Delta_{i \text { pool }}>1.6 \% \Rightarrow$ fail. The cause of the discrepancy should be investigated.

We propose to control a convergence of the assay results as a measure of their uncertainty. The confidence interval for a single assay result should not exceed $U_{\text {target }}=1.6 \%$. To heighten reliability of decision-making, the analysis can be repeated using additional 20 tablets. The confidence interval $\left(\Delta_{i \text { pool }}\right)$ of the pooled $R S D$ and combined number of degrees of freedom $d f=(4-1)+$ $+(4-1)=6$ (instead of $d f=4-1=3$ ) should be calculated in this instance. However, if the calculated confidence interval for the first four analyses is large enough and requirements for $\Delta_{i \text { pool }}$ are not met when performing additional four analyses, even if their $R S D=0$, the test is stopped.

For routine analyses, a more straightforward acceptance criterion is proposed: compare assay results for the first and fourth test portions since in that case, the effect of a systematic shift towards an increase in the assay results is most clearly manifested:

Assay results obtained for the first and fourth test portions should not differ by more than $2.3 \%$ (as two independent analysis results are compared, each of which may have an uncertainty of no more than $U_{\text {target }}$, they can differ by no more than $U_{\text {target }} \times \sqrt{2}=2.3 \%$ ).

To verify the feasibility of the proposed analytical procedure, we conducted its transfer. Besides, for the results obtained, the equation of the regression line was calculated, from which the significance of the slope and the difference between calculated assay values for the first and fourth analysis were checked. 
The results obtained in the receiving unit (RU) are shown in Table 4.

Table 4 illustrates that in RU, the test sample is characterised by acceptable homogeneity, which is evidenced by admissible difference between assay results (1.19; criterion: $\left|x_{1 \text { Calc }} \quad x_{\max \text { Calc }}\right| \quad 2.3 \%$ ) and insignificance of the slope of the regression line. The requirements for $\Delta_{i}$ are met.

Table 4

Results of desloratadine assay and calculation obtained for the test portion of $420 \mathrm{mg}$ in RU during method transfer

\begin{tabular}{|c|c|c|}
\hline $\boldsymbol{n}_{\boldsymbol{i}}$ & $\boldsymbol{m}_{\boldsymbol{i}}, \mathbf{m g}$ & $\boldsymbol{x}_{\boldsymbol{i}}, \mathbf{\%}$ \\
\hline 1 & 401.2 & 98.3 \\
\hline 2 & 400.9 & 99.5 \\
\hline 3 & 403.1 & 99.7 \\
\hline 4 & 408.0 & 99.5 \\
\hline \multicolumn{2}{|c|}{ Mean } & 99.3 \\
\hline \multicolumn{2}{|c|}{ Acceptance criteria } & 1.51 \\
\hline$\left|x_{1 \text { Calc }} x_{\text {max Calc }}\right|$ & $\Delta i \leq 1.6 \%$ \\
\hline Acceptance criteria & 1.19 \\
\hline
\end{tabular}

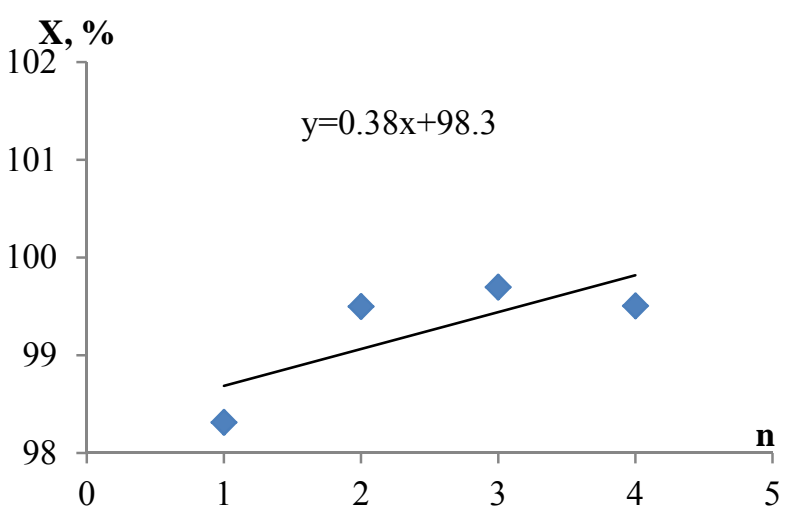

Fig. 4. Assay results obtained for the test portion of $420 \mathrm{mg}$ and the regression line in RU during method transfer

However, the difference between the assay results obtained for the first and fourth test portions $\left|x_{1 \text { Calc }} x_{\max \text { Calc }}\right|$ is greater in RU compared to those obtained in the Sending Unit (SU) - 1.19 as opposed to 0.08. $\Delta_{i}$ is also much greater in RU than in SU $(1.51 \%$ as opposed to $0.65 \%$ ) and is very close to the critical value $\left(U_{\text {target }}=1.6 \%\right)$.

This confirms subjectivity of the visual control over homogeneity of the test sample prepared by manual tablet grinding and the need for objective control over this source of variability in assay results during routine analyses.

\section{Discussion}

Several works reported a discrepancy in assay results associated with inhomogeneity of the powder bed obtained by grinding of tablets to be served as a test sample $[9,10]$. Variability in assay results was also observed when deve- loping and validating an assay procedure for quantification of desloratadine in film-coated tablets on the manufacturer's premises (PJSC SIC "Borshchahivskiy CPP", Ukraine), where a test sample was obtained in the same fashion. Since there was difficulty using another technique, manual grinding of desloratadine tablets was chosen for the test sample preparation.

To achieve sufficient homogeneity of the test sample and reduce the risk of variability in assay results, amendments to the manufacturer's procedure were made, and acceptance criteria were laid down. The proposed solutions were experimentally justified.

The use of the test portion equivalent to the weight of four tablets minimizes the risk of aberrant results of the assay of desloratadine in film-coated tablets Alerdez manufactured by PJSC SIC "Borshchahivskiy CPP”, Ukraine.

Study limitations. Acceptance criteria for managing the risk of inconsistent assay results associated with inhomogeneity of the test sample were established following an approach of the State Pharmacopoeia of Ukraine and the principle of insignificance. They targeted at the pharmaceutical preparation Alerdez, $5 \mathrm{mg}$ desloratadine film-coated tablets manufactured by PJSC SIC "Borshchahivskiy CPP", Ukraine. Consequently, the acceptance criteria and procedure for method transfer proposed in this paper may not be transferred to other tablets of desloratadine due to differences in national regulatory requirements or adopted approaches, pharmaceutical composition, technology, and/or analytical procedure, although can be useful for providing solutions that deal with the issue of assay result variability.

Prospects for further research. The procedure developed for quality control of desloratadine assay results can be used for personnel testing or investigation of out-of-specification results.

\section{Conclusions}

1. The variability in assay results of desloratadine in film-coated tablets Alerdez associated with inhomogeneity of the test sample prepared with the aid of manual tablet comminution was studied.

2. An experiment design to study the influence of the test sample inhomogeneity on the variability in assay results was laid down.

3. Based on the principle of insignificance and recommendations of the State Pharmacopoeia of Ukraine to the target measurement uncertainty, acceptance criteria for the assessment of homogeneity of the test sample by assay results were established.

4. A theoretical prognosis for the minimum test portion mass required to achieve sufficient homogeneity of the test sample and minimize the risk of obtaining inaccurate assay results to an acceptable level was made and experimentally verified.

5. A procedure suitable for the use in routine analysis and as an element of the method transfer and analytical control strategy, as well as acceptance criteria for assay results, was developed. Its feasibility was experimentally proved during method transfer. In the receiving unit, the acceptance criteria were fulfilled.

\section{Conflict of interests}

The authors declare that they have no conflicts of interest. 


\section{References}

1. Nickerson, B. (2011). Sample Preparation of Pharmaceutical Dosage Forms : challenges and strategies for sample preparation and extraction. Boston: American Association of Pharmaceutical Scientists. doi: http://doi.org/10.1007/978-1-4419-9631-2

2. European Medicine Agency (1991). 3AQ11a. Specifications and Control Tests on the Finished Product. London, 83-94.

3. Bánfai, B., Ganzler, K., Kemény, S. (2007). Content uniformity and assay requirements in current regulations. Journal of Chromatography A, 1156 (1-2), 206-212. doi: http://doi.org/10.1016/j.chroma.2006.10.067

4. The European Pharmacopoeia. 10th Ed. Suppl. 2. (2020). 2.9.40. Uniformity of dosage units. Available at: https://pheur.edqm.eu/ Last accessed: 03.08.2020

5. Harrington, B., Nickerson, B., Guo, M. X., Barber, M., Giamalva, D., Lee, C., Scrivens, G. (2014). Sample Preparation Composite and Replicate Strategy for Assay of Solid Oral Drug Products. Analytical Chemistry, 86 (24), 11930-11936. doi: http://doi.org/10.1021/ac503551r

6. Leontev, D., Grizodub, A., Volovik, N., Petrus, V. (2018). Kriteriy priemlemosti minimalno dopustimogo chisla tabletok dlya rascheta rezultatov kolichestvennogo opredeleniya. Nauchnyiy forum: meditsina, biologiya i himiya, 1 (9), $72-78$.

7. Leontev, D., Petrus, V., Grizodub, A., Volovik, N. (2018) Kolichestvennoe opredelenie i odnorodnost dozirovannyih edinits: effektyi neodnorodnosti i obespechenie kachestva. Farmakom, 2, 45-55.

8. Benes, L. (2019). The Importance of Comminution in Pharmaceutical Analysis. Drug Discovery and Pharmaceuticals. Available at: https://www.labmate-online.com/article/laboratory-products/3/fritsch-gmbh/the-importance-of-comminution-in-pharmaceutical-analysis/ 2540 Last accessed: 02.08 .2020

9. Greco, G. (1985). III Segregation of Active Constituents from Tablet Formulations During Grinding: Effects on Coated Tablet Formulations. Drug Development and Industrial Pharmacy, $11 \quad$ (9-10), $1889-1899 . \quad$ doi: http://doi.org/10.3109/03639048509057705

10. Ducette, Y. (1987). Variability of Assay Results for Hydralazine Hydrochloride Tablets Due to the use of Electirc Mill Comminution During Sample Preparation. Drug Development and Industrial Pharmacy, 13 (2), 289-302. doi: http://doi.org/10.3109/03639048709040173

11. Rossbach, M., Grobecker, K.-H. (1999). Homogeneity studies of reference materials by solid sampling - AAS and INAA. Accreditation and Quality Assurance, 4 (12), 498-503. doi: http://doi.org/10.1007/s007690050422

12. Volovyk, N., Leontiev, D., Gryzodub, O. (2019). The approach of the State Pharmacopoeia of Ukraine to the homogeneity study of pharmacopoeial reference standards. EDQM \& USP. Strasbourg, 13-14.

13. Takano, D. E. N., de Souza Reis, P. R., Singh, A. K., Lourenço, F. R. (2017). Estimation of uncertainty for measuring desloratadine in tablets formulation using UV spectrophotometry. Measurement, 101, 40-44. doi: http://doi.org/10.1016/ j.measurement.2017.01.018

14. Derzhavna Pharmakopeya Ukrayini. Vol 1 (2015). Kharkiv: DP «Ukrayinskiy naukoviy farmakopeyniy tsentr yakosti likarskih zasobiv», 1128.

15. Mohammad, Y., Pragati Kumar, B., Srinivas, R., Rehana, S. K. (2010). New UV spectrophotometric method for the determination of desloratadine in bulk and tablet dosage forms. Journal of Chemical and Pharmaceutical Sciences, 3 (4), $241-243$.

16. Hussain Raviteja, K., Nasare, M., Prasad, V. V. L. N., Diwan, P. V. (2014). UV Spectrophotometric Method for the Simultaneous Determination of Desloratidine and Pseudoephedrine $\mathrm{HCl}$ in Combined Dosage Form. British Journal of Pharmaceutical Research, 4 (4), 418-428. doi: http://doi.org/10.9734/bjpr/2014/5615

17. Ravi Challa, R., Naidu, N. (2016). Development and validation of stability indicating RP-HPLC method for Simultaneous determination of Desloratadine and Montelukast Sodium in pharmaceutical dosage form. International Journal of Pharmacy and Analytical Research, 5 (2), 294-309.

18. Mallapu Rani, E., Hindustan Abdul, A., Sreenivasulu, R., Rani M., Giri, M., Reddy, K. K. et. al. (2011). Spectrophotometric Determination of Desloratadine in Pharmaceuticals by Using Difference Spectrophotometric Method. Journal of Pharmacy Research, 4 (3), 730-731.

19. Roge, A., Shendarkar, G., Ghante, M., Ghiware, N. (2019). Development of Validated UV Spectrophotometric Stability Indicating Method for Estimation of Desloratadine from Its Tablet Dosage Form. International Journal of Pharmacy and Biological Sciences, 9 (3), 1174-1181.

20. Çğalar, S., \& Öztun, A. (2007). A Sensitive Spectrophotometric Method for the Determination of Desloratadine in Tablets. Journal of AOAC INTERNATIONAL, 90 (2), 372-375. doi: http://doi.org/10.1093/jaoac/90.2.372

21. The International Conference on Harmonisation of Technical Requirements for Registration of Pharmaceuticals for Human Use (2005). VALIDATION OF ANALYTICAL PROCEDURES: TEXT AND METHODOLOGY Q2R1 Current Step 4 version: ICH Harmonised Tripartite Guideline.

22. WHO Expert Committee on Specifications for Pharmaceutical Preparations (2016). Technical Report Series, No. 996. Annex 1: Good pharmacopoeial practices. Geneva: World Health Organization. Available at: https:/www.who.int/medicines/publications/pharmprep/ WHO_TRS_996_web.pdf

23. The United States Pharmacopeia (2020). Desloratadine Tablets. Available at: https://online.uspnf.com/uspnf/ Last accessed: 01.08 .2020 
24. Leontiev, D., Volovyk, N. (2016). Specificity of application of the uncertainty concept to the decision on compliance of medicines. Arhiv za farmaciju, 66, 207-208.

25. ISO 17034:2016 General requirements for the competence of reference material producers (2016). International Organization for Standardization.

26. The United States Pharmacopeia (2020). <1220> Analytical Procedure Lifecycle. Pharmacopeial Forum, 46 (5).

Received date 07.08.2020

Accepted date 24.09.2020

Published date 30.10 .2020

Dmytro Leontiev, Doctor of Pharmaceutical Sciences, Senior Researcher, Head of Department, Department of Validation and Reference Standards, State Enterprise "Ukrainian Scientific Pharmacopoeial Center for the Quality of Medicines", Astronomichna str., 33, Kharkiv, Ukraine, 61085, Professor, Department of Pharmaceutical Chemistry, National University of Pharmacy, Pushkinska str., 53, Kharkiv, Ukraine, 61002

E-mail: leontievd@yahoo.com

Vasyl Petrus, Postgraduate Student, Department of Pharmaceutical Chemistry, National University of Pharmacy, 53, Pushkinska Str., Kharkiv, Ukraine, 61002, Engineer, Research and Implementation Laboratory, PJSC SIC « Borshchahivskiy CPP», Myru str., 17, Kyiv, Ukraine, 03134

E-mail: petrus.vasyl@gmail.com

Natalia Volovyk, PhD, Department of Validation and Reference Standards, State Enterprise "Ukrainian Scientific Pharmacopoeial Center for the Quality of Medicines", Astronomichna str., 33, Kharkiv, Ukraine, 61085

E-mail: nvolovyk_rs@ukr.net

Oleksandr Gryzodub, Doctor of Chemical Sciences, Professor, Chief Researcher, Department of State Pharmacopoeia of Ukraine, State Enterprise "Ukrainian Scientific Pharmacopoeial Center for the Quality of Medicines", Astronomichna str., 33, Kharkiv, Ukraine, 61085

E-mail: o.gryzodub@gmail.com 